\title{
Histiocytic Sarcoma of Tibia: A Rare Case Report and Review of Literature
}

\author{
Ajita Kendre ${ }^{1}$ Bhooshan Zade ${ }^{1}$ Prasant Chandra ${ }^{2}$ \\ ${ }^{1}$ Indrayani Hospital \& Cancer Institute, Alandi Devachi, Pune, \\ Maharashtra, India \\ 2 Ruby Hall Clinic, Pune, Maharashtra, India
}

South Asian J Cancer 2022;11(2):172-174.
Address for correspondence Ajita Kendre, DNB Radiation Oncology, Indrayani Hospital \& Cancer Institute, Shree Narsimha Saraswati Medical Foundation, Alandi-Chakan Road, Alandi Devachi, Khed, Pune, Maharashtra, 412105, India (e-mail: ajita.kendre@gmail.com).

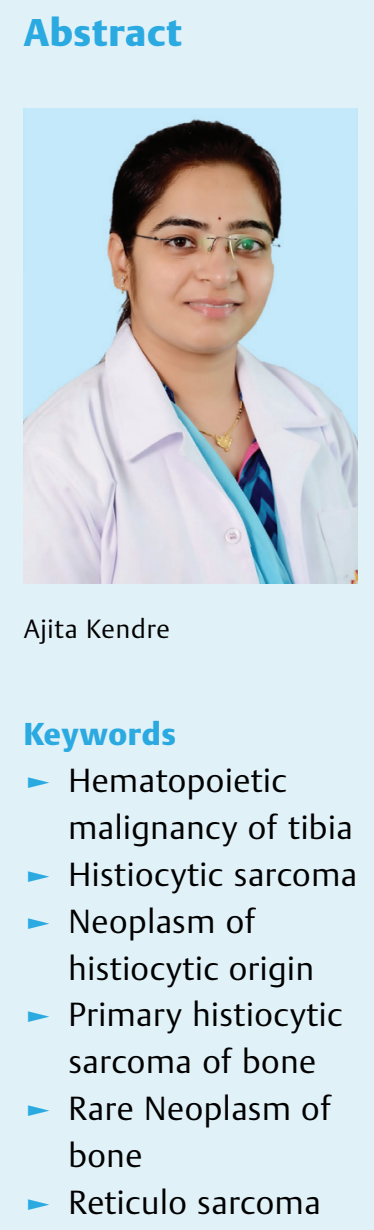

Histiocytic sarcoma is a rare disorder and there has been a lot of confusion and debate regarding its diagnosis and treatment. The World Health Organization (WHO) in 2008 aided in the standardization of diagnosis of histiocytic sarcoma; however, the treatment protocols are still not clear and the treatment is on the line of other hematological malignancies.

This study intends to report a rare case of histiocytic sarcoma and the treatment protocol used and analysis of available literature. The usual sites of histiocytic sarcoma are the lymphoreticular system, skin, and gastrointestinal tract, but solitary bone involvement is rare.

This disease being a localized one was treated locally with surgical curettage followed by radical radiation therapy. Systemic therapy was not offered to this patient and has been reserved in case a patient gets a systemic recurrence as done in most cases of $B$ cell lymphoma.

Based on follow-up until now, the patient is disease-free and doing well. Thus, this treatment protocol appears apt for this concerned patient; however, there is a need for a large-scale analysis of various reported cases to establish a standardized treatment protocol for this rare and aggressive disease.
DOI https://doi.org/10.1055/s-0041-1739180 ISSN 2278-330X

How to cite this article: Kendre A, Zade B, Chandra P, et al. Histiocytic Sarcoma of Tibia: A Rare Case Report and Review of Literature South Asian J Cancer 2022;11(2):172-174. (c) 2022. MedIntel Services Pvt Ltd. All rights reserved.

This is an open access article published by Thieme under the terms of the Creative Commons Attribution-NonDerivative-NonCommercial-License, permitting copying and reproduction so long as the original work is given appropriate credit. Contents may not be used for commercial purposes, or adapted, remixed, transformed or built upon. (https://creativecommons.org/licenses/by-nc-nd/ 4.0/)

Thieme Medical and Scientific Publishers Pvt. Ltd., A-12, 2nd Floor, Sector 2, Noida-201301 UP, India 


\section{Introduction}

Histiocytic sarcoma is an extremely rare malignant neoplasm of the hematopoietic system with poor prognosis, literature quotes its incidence of less than $1 \%$ of all hematolymphoid neoplasms. ${ }^{1}$ It is characterized by morphological and immunophenotypic features similar to those of mature tissue histiocytes. There are expressions of histiocytic markers without dendritic cell markers. Neoplastic proliferation associated with acute monocytic leukemia should be excluded. Because a subset of cases occurs post mediastinal germ cell tumor, particularly malignant teratoma and teratocarcinoma are known to differentiate along hematopoietic lines. Thus, it is suggested that histiocytic sarcoma arises from pluripotent germ cells. ${ }^{2}$

Clinically, it presents as a solitary mass that may be associated with fever and weight loss. Other less common systemic features are lytic bony lesions, hepatosplenomegaly, and pancytopenia. Three typical sites of involvement are lymph nodes, skin, and the gastrointestinal system. ${ }^{3}$ Immunohistochemically, these tumors are positive for one or more histiocytic markers such as the cluster of differentiation (CD) 68 (KP1, PGM1), CD1 63, and lysozyme, but negative for CD1 a, CD21, CD35, CD30, and T cell, B cell, and myeloid lineage markers. S1 00 can be positive but is usually weak or focal. Ki67 is variable. With the development of immunohistochemical (IHC) techniques, most previous reported cases of HS are now generally recognized to be misdiagnosed examples of non-Hodgkin lymphomas, predominantly diffuse large B cell lymphoma or anaplastic cell lymphoma. ${ }^{4}$ Thus, histiocytic sarcoma is a frequently misdiagnosed and underreported entity. This case report aims at reporting a rare incidence of histiocytic sarcoma at an atypical site, i.e, tibial condyles.

\section{Case Report}

A 70-year-old female patient presented with pain and swelling in the left knee joint since 2 months, with a tender hard swelling fixed to the bone. The X-ray of the left knee joint showed a lytic lesion in the medial condyle of the left tibia. MRI showed a well-defined, lytic, eccentric, expansile lesion in epimetaphysis of the proximal tibia ( - Fig 1a, b). Biopsy was performed and histological features were suggestive of high-grade sarcoma with possibilities of histiocytic sarcoma and epitheloid sarcoma. IHC was suggestive of EMA S1 00 SMA focally positive, strongly positive for vimentin, CD 68 diffusely positive, LCA, HLA DR lysozyme positive, suggestive of high-grade sarcoma consistent with histiocytic sarcoma. Blood investigations showed red blood cell (RBC) counts as $4.15 \times 10^{6} / \mu \mathrm{L}$, white blood cell (WBC) count: $11,000 / \mu \mathrm{L}$, and platelet count: $2.92 \times 10^{5} / \mathrm{mm}^{3}$. Bone marrow biopsy did not reveal any malignant infiltration. PET CT showed localized increased metabolic uptake but no evidence of distant spread (-Fig. 2a, b).

The case was discussed by the multidisciplinary tumor board. In view of the localized disease, a plan for surgical
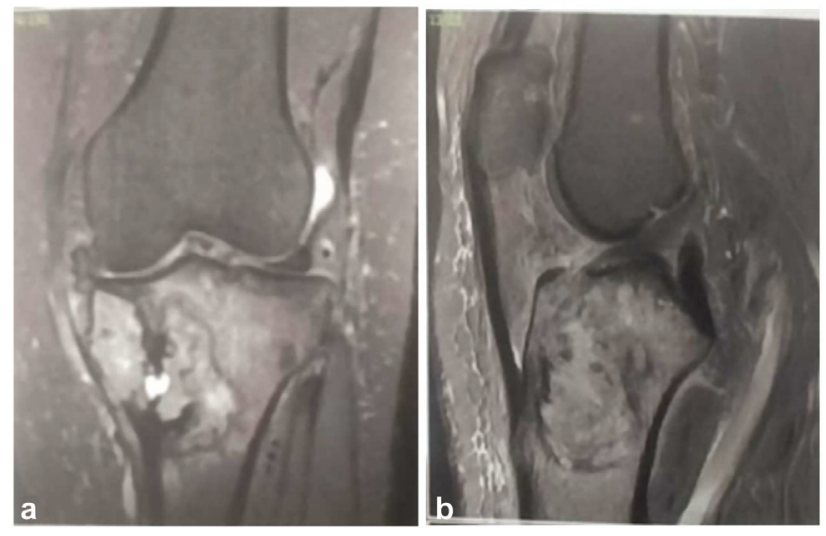

Fig. 1 (a) MRI coronal section through left knee joint showing lytic lesion in the medial condyle of the tibia. (b) MRI sagittal section through the left knee joint. MRI, magnetic resonance imaging.
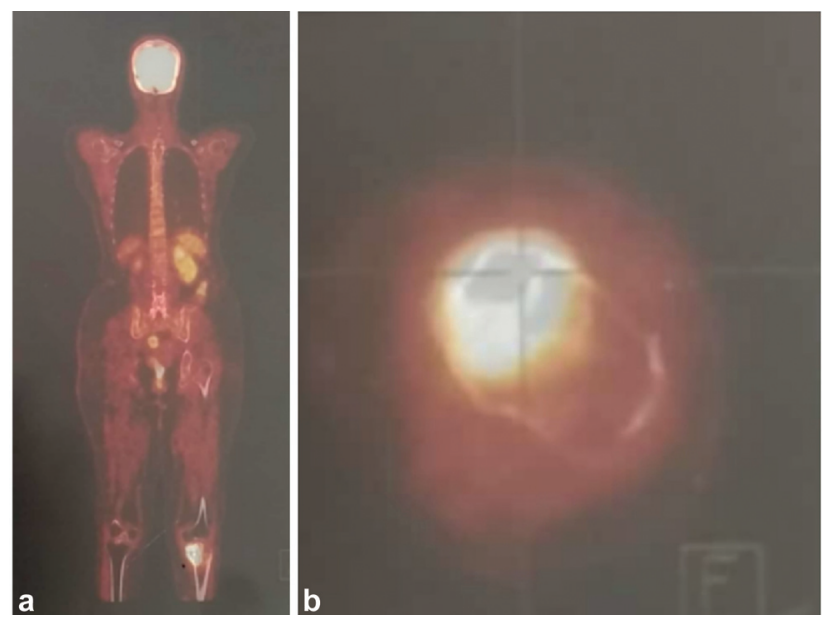

Fig. 2 (a) and (b) PET CT scan showing the FDG avid lesion in the medial condyle of the left tibia and no distant metastasis. FDG: 18Fluro Deoxy Glucose PET CT, positron emission tomography-computed tomography.

treatment was made. Because excision would have led to joint morbidity, curettage of bone marrow was done followed by local radiation therapy ( 45 Gy in 25 fractions, 5 days a week over 5 weeks) with the IMRT: Intensity Modulated Radiotherapy technique. Until the recent follow-up after 1.5 years of diagnosis, the patient is disease-free.

\section{Discussion}

The term histiocytic sarcoma was used by Mathe in 1970 for an entity earlier known by terms such as "reticulosarcoma”(Oberling), "recticulum cell lymphosarcoma" (Silhol), and "retothelsarcom" (Roulet). ${ }^{5}$ However, its description at that time was purely based on morphological similarity to macrophages. Since then, attempts to establish its identity in histiocytic cell lineages by immunohistochemical and cytochemical methods is going on. At present, several markers are being used to establish the diagnosis of histiocytic malignancies such as the cluster of differentiation (CD) 68 (KP1, PGM1), CD1 63, and lysozyme. CD1 63, a hemoglobin 
scavenger receptor protein, is a novel marker used for identifying histiocytic cells with a greater degree of specificity and is a promising marker in the diagnosis of true histiocytic malignancies. ${ }^{3,6,7}$ The World Health Organization (WHO) defines histiocytic sarcoma as a malignancy with morphologic and immunophenotypic features that resemble those of mature tissue histiocytes. ${ }^{8}$

The role of cytogenetics in diagnosis by studying TCR rearrangement or the absence of the $\operatorname{IgH}$ gene has been studied and verified. ${ }^{9}$ In 2001, the WHO stated that the absence of these genetic features is mandatory for the establishment of the diagnosis of histiocytic sarcoma. ${ }^{1}$

This being a rare malignancy, a standard treatment regime is lacking. Treatment is mostly on the lines of large cell lymphoma. ${ }^{10}$ Studies have shown a relation of histiocytic sarcoma with B cell lymphoma lineage. Further studies have also shown two subtypes M1 and M2 macrophages, whose role in the diagnosis and treatment planning is yet to be established. ${ }^{11}$ Biological closeness of histiocytic sarcoma with lymphoma indicates similar prognostic values and treatment lines. For localized disease, surgical resection with or without radiotherapy is indicated, while the systemic disease is treated with chemotherapy regimens such as CHOP, CHOEP, and ICE. Evidence exists for other systemic treatment options with targeted therapies such as alemtuzumab in histiocytic proliferative disorders but further work is required before drawing any conclusions. ${ }^{12}$

Histiocytic sarcoma primarily affecting bone is a rare entity. Although secondary bone involvement as a part of systemic disease is a well-known entity, the primary bone involvement by histiocytic sarcoma is sparsely reported in the literature. Lage et al reported disseminated primary bone disease that was confused with multiple myeloma. ${ }^{13}$ They treated the patient with localized radiotherapy and systemic therapy. Bhalla et al described a primary bone histiocytic sarcoma in the head and neck. The patient was being treated with systemic therapy. ${ }^{14}$ Our patient had a lesion in the tibial bone marrow. Because it was a completely localized disease and was completely excised, systemic therapy was not advocated.

Conflict of Interest

None declared.

\section{References}

1 Grogan TM, Pileri SA, Chan JKC, et al. Histiocytic sarcoma. In: Swerdlow SHCE, Harris NL, et al., eds. WHO Classification of Tumours of Haematopoietic and Lymphoid Tissues. 4. Lyon: International Agency for Research on Cancer; 2008:356-357

2 Weiss LM, Grogan TM, Mueller-Hermelink HK, et al. Histiocytic sarcoma. In: Jeff ES, Harris NL, Stein H, Vardiman JW, et al., eds. World Health Organization Classification of Tumors: Pathology and Genetics of Tumors of Haematopoietic and Lymphoid Tissues. Lyon: International Agency for Research on Cancer Press; 2001:278-279

3 Tefferi A, Dan L, Longo . Less Common Hematologic Malignancies. In: J. Larry Jameson, Robert G. Dunlop, Ruth Perelman, Stephen L. Hauser, Robert A. Fishman, Joseph Loscalzo, eds. Harrison's Principles of Internal Medicines. 20th ed. McGraw-Hill Education; 2018:792

4 Zhao J, Niu X, Wang Z, Lu H, Lin X, Lu Q. Histiocytic sarcoma combined with acute monocytic leukemia: a case report. Diagn Pathol 2015;10:110. Doi: 10.1186/s1

5 Mathé G, Gerard-Marchant R, Texier JL, Schlumberger JR, Berumen L, Paintrand $M$. The two varieties of lymphoid tissue "reticulosarcomas", histiocytic and histioblastic types. Br J Cancer 1970;24(04):687-695

6 Kristiansen M, Graversen JH, Jacobsen C, et al. Identification of the haemoglobin scavenger receptor. Nature 2001;409 (6817):198-201

7 Walter RB, Bächli EB, Schaer DJ, Rüegg R, Schoedon G. Expression of the hemoglobin scavenger receptor (CD163/HbSR) as immunophenotypic marker of monocytic lineage in acute myeloid leukemia. Blood 2003;101(09):3755-3756

8 Jaffe ES, Harris NL, Stein H, Vardiman JW, eds. Pathology and Genetics of Tumours of Haematopoietic and Lymphoid Tissues. Lyon: IARC Press; 2001:273-290

9 Hanson CA, Jaszcz W, Kersey JH, et al. True histiocytic lymphoma: histopathologic, immunophenotypic and genotypic analysis. $\mathrm{Br} \mathrm{J}$ Haematol 1989;73(02):187-198

10 Sohn BS, Kim T, Kim JE, et al. A case of histiocytic sarcoma presenting with primary bone marrow involvement. J Korean Med Sci 2010;25(02):313-316

11 Takahashi E, Nakamura S. Histiocytic sarcoma: an updated literature review based on the 2008 WHO classification. J Clin Exp Hematop 2013;53(01):1-8

12 Cruz-Chacon A, Mathews J, Ayala E. Transplantation in rare lymphoproliferative and histiocytic disorders. Cancer Contr 2014;21(04):335-342

13 Lage LAPC, Albuquerque VJ, Moraes RDR. Primary histiocytic sarcoma of bone with disseminated involvement - initial presentation mimicking multiple myeloma: the atypical face of a rare neoplasm. Ann Hematol Oncol 2019;6(09):

14 Bhalla $\mathrm{V}$, Khan $\mathrm{N}$, Jones $\mathrm{M}$, et al. A rare case of paediatric histiocytic sarcoma of the maxilla and mandible. Dentomaxillofac Radiol 2016;45(06):20150393 